\title{
Stabilization of endangered part of structures by building dry brunt brick buttressing, critical case study of plane wall in DKG-North Area, Mohenjo daro
}

\author{
J.M. Shaikh, ${ }^{\mathrm{a}, *}$, JaeSeung Park ${ }^{\mathrm{b}}$ \\ ${ }^{a}$ PhD candidate; EMDiReB (European Masters of Building repair and Diagnosis) Erasmus Mundus (Spain, Italy and Polannd), \\ M.Arch (Low Energy House Design, Lahore), B.Arch (Indus Valley School, Karachi) \\ javeria@hanyang.ac.kr \\ ${ }^{\mathrm{b}}$ Ph.D., NCARB, FKIA, Professor, \\ ${ }^{a}$ School of Architecture, Hanyang University ERICA campus, South Korea \\ jaespark@hanyang.ac.kr
}

KEY WORDS: Anastolysis process, generalized structural deformations, Shear Walls, Materials for restoration:

\begin{abstract}
:
'World Heritage Sites' are places or buildings of outstanding universal value recognized as constituting a world heritage 'for whose protection it is the duty of the international community as a whole to co-operate'. The concept of World Heritage is at the core of the World Heritage Convention, adopted by Heritage List as a means of identifying, protecting, conserving and presenting those parts of the world's natural and cultural heritage that are of sufficient 'outstanding universal value' to be the responsibility of the international community as a whole. By joining the Convention, nation states are pledged to safeguard the WH S by protecting their national heritage. UNESCO in 1972, to which 160 nations have now been adhered. The Convention came into force in 1975 and established a Site in their territory as part of a universally agreed policy for World.

Moenjodaro site covering an area of 555 Acres out of which only $10 \%$ of it has been excavated by exposing 50 Kilometer standing walls. The wall of the main street of DK G Area, Mohen jo Daro partially deformed, due to the torque effects this is studied here on a lateral cross wall in the chief house. Furthermore, the resulting behaviour of the bucking wall demonstrates the significant loadbearing capacity of the structure under service conditions and its high sensitivity to imposed changes of the geometry. Although the tensile stresses exceeded the flexural strength at the vertices and the length of the wall, hence both the geometry and condition of this area are critical for the safety of the wall. The results of this study can improve the assessment and thus help in the preservation of many important structures of the metropolitan city. Here the hydrous characteristic of the brick is studied as a general phenomenon, it is observed that the remains of the sites located in Sindh suffered a lot mostly due to age, human neglect variations of atmospheric condition, severe temperature and natural disasters.

The main causes of decay are summarised as: Salt Action and moisture in filtration from ground and atmosphere direct rains

Has also resulted in structural distress including extreme thermal stress, poor site drainage, material decay and visitors behaviour. Hence the brick material is "tired" to performance and its durability decreases under different influences for varying reasons, the causes of decay are material properties or structure properties or by environmental influences thus repair ${ }^{1}$ is required. The aim of this paper is to study the main deformation affecting Moenjodaro structures, an archaeological site that prospered from 2350 to 1800 $\mathrm{BC}$, thermal stress causing walls to lean and decay structurally.
\end{abstract}

\section{INTRODUCTION}

Moenjodaro, the principal Indus Valley Civilization site, is situated at about 465 kilometer north of Karachi and is being commonly and equally cherished all over the globe out of 851 different properties as of 2007, World Heritage Sites like wise as an irreplaceable Cultural Heritage of Mankind. Moenjodaro site attracted attention of the scholars of several countries under the umbrella of UNESC, before the inscription of the site on World Heritage List.

World Heritage Sites are places or buildings of outstanding universal value recognized as constituting a world heritage 'for whose protection it is the duty of the international community as a whole to cooperate'.

The historical importance of the Moenjodaro is recognized nationally and internationally. In 1980, the Moenjodaro was inscribed as a cultural World Heritage Site under the United Nations Educational, Scientific and Cultural Organization (UNESCO) 1972 World Heritage
Convention. This rare and prestigious designation acknowledges its outstanding universal value. The Moenjodaro is owned by the Pakistan, and the whole site is a Conservation Area. There can be few - if any - places which enjoy such a level of recognition and protection. The Archaeological Remains of Moenjodaro are located on the right bank of Indus River about $510 \mathrm{~km}$ North-East of Karachi and $28 \mathrm{~km}$ away from Larkana District in the Province of Sindh, It represents the metropolis of the Indus Civilization which is the third great ancient civilization in human history. This great civilization was flourished approximately between $2500 \mathrm{BC}-1500 \mathrm{BC}$ in the Indus Valley. The discovery at Moenjodaro in 1922 has unveiled an amazing story of the well planned layout based on grid of streets comparable to that of present day New York having structures constructed of baked bricks buildings with the World's first urban sanitation systems advanced drainage system and elaborate public bath area, college of Priests and a large state granary, bears testimony that it was a metropolis of great importance enjoying a well organized civic, economic, social and cultural system. How this one of the great metropolis

\footnotetext{
* Corresponding author. This is useful to know for communication with the appropriate person in cases with more than one author.

${ }^{1}$ Repair is a replacing or correction of technical and performance properties of a material (element, structure, and building) to certain serviceability and durability.
} 
(another at Harappa District, Sahiwal) of Indus Civilization came to its tragic end, is still an enigma. Many factors have been attributed to the collapse and ultimate disappearance of this great civilization. The citadel area contains administrative and religious building while the low mound or the lower city represents residential quarters, shopping areas and other important buildings. Each area has been given a particular name (which is derived from the name of principal excavator who worked in the area), such as S.D. Area, D.K. Area, H.R. Area, V.S. Area, L. Area, M.N. Area and D. Area. The structural remains at Moenjodaro started deteriorating from Salt, Drainage and Thermal problems soon after their excavation. The continuous rise of ground water table including the salt taken moisture to more into the structures through capillary action, consequent upon the construction of Sukkur Barrage and its network of canals in 1932, had accelerated the speed of its deterioration. The brick walls are in danger of collapse due to their surface decay and structural distress by hydration/dehydration process of salt, rain and extreme thermal stress. The river Indus showed a tendency to move westward toward the remains, threatening the very existence of the site.

\section{EFFECTS AND SOURCE OF MOISTURE}

The destructive effects of salts are usually only realized if moisture is variable to dissolve, transport and to deposit them the pores of porous materials. In addition moisture can degrade brick by dissolving slightly soluble cementations materials. Main source of the moisture in the walls of Moenjodaro are probably rain water, drainage and runoff water, and ground water. In addition, during periods of high relative humidity, some moisture may be condensing from the atmosphere within the walls.

\subsection{Rain Water}

The amount of rain water entering the walls has not been measured. However, driving rains usually do not easily enter walls made from burnt bricks and mud mortar. Most rain water probably penetrates the walls through their top surface rather then through their sides. This is because rain water striking the top surfaces can rapidly erode the mud mortar producing deep cavities in which water can accumulate and enter the walls. The salts at Moenjodaro have been attributed to a variety of sources including ground water carrying salts to the surface by capillary action, and it is considered that salts were in the brick at the time of preparation. The quantification of salts available at Moenjodaro has been summarized in the Table \& chart below:

\begin{tabular}{|r|r|r|}
\hline \multirow{2}{*}{} & \multicolumn{2}{|c|}{ Reading } \\
\cline { 2 - 3 } & Surface & 200 CM depth \\
\hline 2001 & 4620.80 & 544.00 \\
\hline 2002 & 4806.40 & 1324.80 \\
\hline 2003 & 4819.20 & 583.68 \\
\hline 2004 & 6092.80 & 1613.20 \\
\hline 2005 & 7680.00 & 2530.20 \\
\hline 2006 & 8960.20 & 2644.20 \\
\hline 2007 & 10512.00 & 1422.80 \\
\hline 2008 & 11314.00 & 1273.6 \\
\hline
\end{tabular}

Table 1. The quantification of salts available at Moenjodaro

\subsection{Drainage and runoff Water}

While relatively small amount of precipitation occur at Moenjodaro (around $127 \mathrm{~mm}$ ) most of it occurs during the few intense rain storms. Such rainfalls do not readily penetrate the fine particle soils which are apparently present at Moenjodaro. Therefore a large amount of drainage and runoff water often accompanies each rain storm and which is the absence of proper drainage system, starts ponding with slumping and eventual collapse of the walls.

\begin{tabular}{|c|c|}
\hline MONTH & ACTUAL READING \\
\hline January, 2012 & $5.211 \mathrm{~m}$ \\
\hline February, 2012 & $5.464 \mathrm{~m}$ \\
\hline March, 2012 & $5.882 \mathrm{~m}$ \\
\hline April, 2012 & $6.189 \mathrm{~m}$ \\
\hline May, 2012 & $6.332 \mathrm{~m}$ \\
\hline June, 2012 & $6.479 \mathrm{~m}$ \\
\hline July, 2012 & $5.691 \mathrm{~m}$ \\
\hline August, 2012 & $5.012 \mathrm{~m}$ \\
\hline September, 2012 & $4.656 \mathrm{~m}$ \\
\hline October, 2012 & $4.356 \mathrm{~m}$ \\
\hline November, 2012 & $4.958 \mathrm{~m}$ \\
\hline December, 2012 & $5.201 \mathrm{~m}$ \\
\hline
\end{tabular}

Table 2. Water \& Soil Investigation Laboratory (WASIL), Mohenjo-Daro, averagely monthly water table actual reading in meters for the year, 2012

\subsection{Ground water capillary Rise}

Ground water can rise from the ground water level up into masonry walls by capillary rise, carrying soluble salts into walls. Usually such process is slow but eventually a large amount of salts can be drawn into masonry walls. Drainage and runoff water also can rise up walls by capillary action. The height that moisture can rise in soil and wall is controlled by a capillary pressure (dependant on the sizes of the capillaries), the evaporation rate, and the permeability of the soil of walls. Considering only the effects of pore size, decreases. Water can also travel in horizontal direction by capillary action. Furthermore, it travels twice as for in a horizontal direction as vertically. At present the water table is $9 \mathrm{~m}$ below the plain level. However, the height, of capillary rise above the water table at Moenjodaro is more than $3 \mathrm{~m}$.

\subsection{Condensation of Moisture}

Condensation of moisture at high relative humanities in brick walls can occur, especially if the dew point is reached within the walls. Condensation of water in capillaries also can occur, especially if the atmosphere relative humidity is $90 \%$ or above. Soluble salts entrapped in brick, however the responsible for the largest amount of hygroscopic (condensed) moisture accumulating in bricks, the amount being several times that condensing in salt free bricks.

2.5 Northward Leaning of East West Oriented Walls.

The primary and serious problem at Moenjodaro in leaning of east west oriented walls towards north. It is understood that this destructive problem was just the result of micro climatic deference which is caused by the sun on the southern facade and shade on the northern face of the east west oriented walls. By last effect the mud mortar on the southern side remains dry 
and consequently strong whereas the mortars on the northern side remains wet for most of the day and therefore work. The deference in the strength of mud mortar of two sides causes the masonry to learn towards weak northern sire. The other factor that aids to the leaning process is the reduction of density of the mortar due to salt effects which is higher in northern side compared to southern side of walls in question, Moreover, the northern face bricks of east west obtained walls are deteriorating at the higher rate as compared to the southern face once. The erosion of mud mortar is higher on northern side as compared to southern side.

No sooner then the lean starts, the surface area of the walls facing the driving rains increase resulting into more saturation and load of the masonry which accelerate the rate of leaning of east west obtained walls.

The leaning walls do not collapse as long as their centre of gravity lies within two third of their width. The moment their centre of gravity cross the two third of the width, no measure can save them from collapse.

\subsection{Salt Action}

The major process responsible for brick deterioration of Moenjodaro has been crystallization soluble salt. The white salt efflorescence appearing on the brick is caused by the crystallization of the soluble salt at surface opening of pores as moisture evaporates, Efflorescence in itself is usually not harmful but does indicate that internal salts and moisture migration is taking place. Closely related to efflorescence but much more harmful is sub-florescence in which the salts crystallized underneath the surface to continually peel and, therefore, it can be very damaging. Desert climates are favourable environments of sub florescence.

Distribution of bricks may also be caused by a considerable difference in the thermal expansion of the brick itself. This process is importance in areas, where a large daily temperature variation occurs, often found in desert Regions. The salts at Moenjodaro have been attributed to a variety of sources including ground water carrying salts to the surface by capillary action, and it is considered that salts were in the brick at the time of preparation.

Approximate coordinates of the site are $27^{\circ} \mathrm{N}$ and $68^{\circ} 8^{\prime} \mathrm{E}$, the climate is arid, and the average rainfall is less than 5 inches per annum. Annually these walls at Mohenjo Daro site experience deformations due to the ground surface subsidence movement with underground varying water table the subsoil consist of about 90 percent of water, the top 50 feet of the soil profile being relatively heavier soil ${ }^{2}$. Under this impact the bases of the walls are disturbed which results in structural deformations and damages. On the one hand, repeated interventions have resulted in structural deterioration and on the other hand, owing to change of ownership requirements to upkeep of archaeology have become more severe.

The timber and iron buttresses installed at the chief house, (Fig. 1) prevents the buckling at one side only. Though this intervention compromised the structural scheme of the building

\footnotetext{
${ }^{2}$ Mohen jo Daro preservation plan, S-1, Summary 1972
}

as shown in Fig. 1, causing an excessive increase of the thrusts on the lateral wall from the external side, which were previously balanced by a system of columns and roof buttresses (original 5000 years ago). In addition the primary design was constantly transmitting loads and balancing it, hence the weight of the upper structure is usually transmitted through the lateral wall upon the pier with an offset. Today this isolated wall is not behaving similarly, but the entire load is being transmitted to the lower end of this wall, which has to fit in the narrow area of the street. The combination of these forces with the thrust of the continuity resulted in the progressive instability of the lateral wall and the formation of minor and major cracks, at the relatively weak area of the wall.

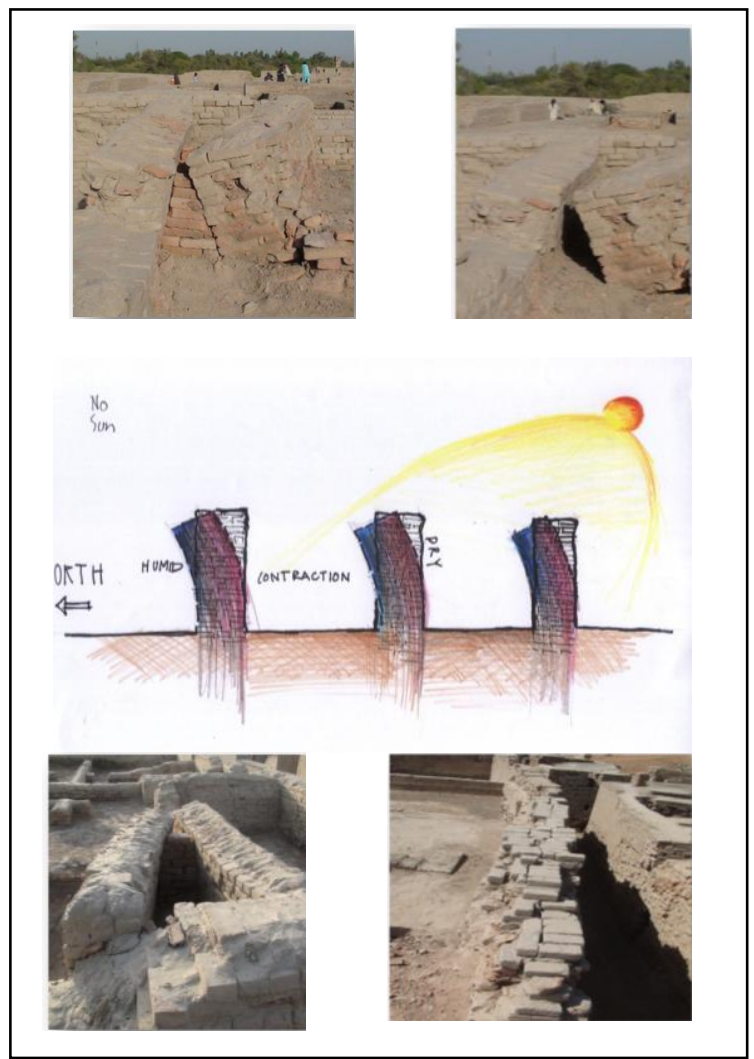

Figure 1. The thermal stress recorded and filling of gaps, voids in mud capping with pure clay in DK area

As a consequence, failure resulted from excessive horizontal displacements, and the critical crack pattern generally follows the scheme in Fig. 2 the longitudinal cracks develop at the extrados parallel to the edges. This pattern has been mainly established through inspections of damaged structures, but no information is available on crack propagation or the distribution of the loads during failure.

\section{DAMAGE TO THE BRICK WALL}

1. Infiltration due to damage in the structure or geometry of the walls.

2. Ascension by capillarity from underground.

3. Condensation of air humidity on cold walls

4. Rain water pushed on the walls by wind

5. Horizontal filtration and condensation 


\subsection{Cross support of the South Street}

The support at the south room, span almost square compartments, and the height of their vertices reaches the middle of the lateral elevation as shown in Figure three. At their outer edge they are supported upon the wall and the attached responds, while the edges of the angular support along the wall rest upon the main foundation Figure three. Transverse pointed angle support mark the edge between the neighbouring bays. The diagonal ribs and the transverse wall have the same plain cross section and they spring from a low buried foundation, while the pockets created between the supports of the wall reach the third of the height. The wall is made of load bearing masonry, composed of long thin slabs of regular thickness.

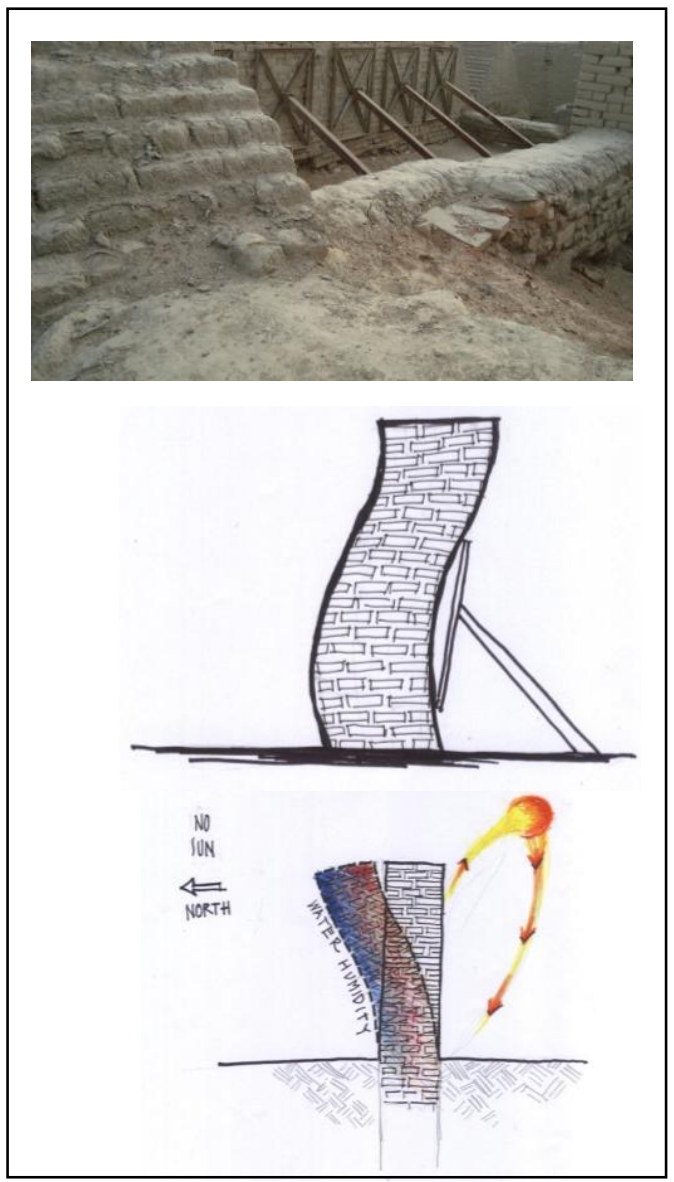

Figure 2a : the exo- skeletal support (30 March, 2012) This is a critical case out of plane wall in DKG-North area.

Figure 2b: Exaggerated deformation pattern in the sectional view, along with the support

\subsection{Collapse of 2012}

In 2000 the extensive decay of the wall prompted the replacement of the bricks with new over burnt bricks, hence the wall become thick. This, however, accelerated the already dangerous state of the walls, few archaeologists surveyed the fabric earlier in 1964 by H.J. Plenderleith and, recorded in many of the walls and piers at some feet height a bulge of 5 to 8 mm toward the north, and concluded that, "the walls and pillars will incline seven or eight inches from the perpendicular that is at the greatest height. He also observed that "there is one of the of the wall fallen down, another just ready to drop away, several of the small columns on the Pillars come away, others fast following; the walls much bent in several places and the whole structure approaching ruin at swift pace.,"

Depending on the types and signs of the ground surface movement it makes different impact on buildings being determined (Fig. 3). At horizontal tensile deformations inclined cracks in external walls are generated which are symmetrical relative to the centre of the wall. Vertical bending and vertical shear cracks are typical of curvature of convexity, the bending cracks being typical of flexible walls where the lengths exceed their heights by more than three times. Shear cracks are always generated, being more typical of two-storey and higher walls than bending crack. Under horizontal compressive deformations and curvature of concavity inclined and horizontal cracks are generated in the walls located symmetrically relative to the centre of the plan.

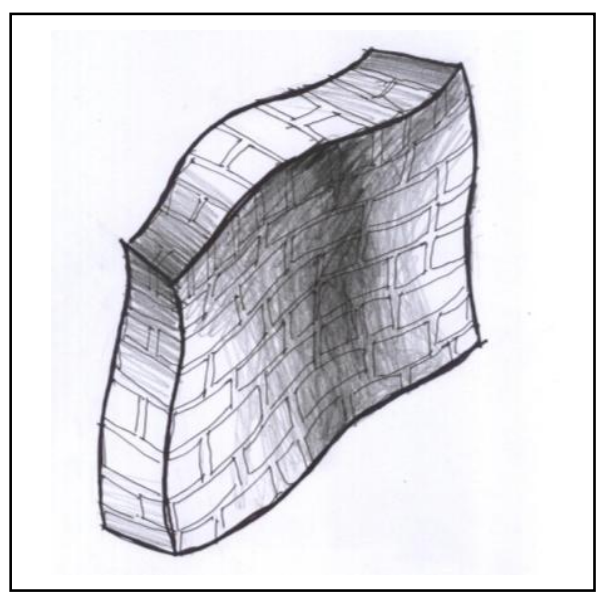

Figure 3: The deformation in a curvilinear form, since the material is tired and is bending with the load (March 2012)

\section{EFFECTS AND SOURCE OF MOISTURE}

The destructive effects of salts are usually only realized if moisture is variable to dissolve, transport and to deposit them the pores of porous materials. In addition moisture can degrade brick by dissolving slightly soluble cementations materials. Main source of the moisture in the walls of Moenjodaro are probably rain water, drainage and run off water, and ground water. In addition, during periods of high relative humidity, some moisture may be condensing from the atmosphere within the walls.

Capillarity $^{3}-\mathbf{h}$

$$
h=\frac{2 \sigma \cos \theta}{r g \rho_{p}}
$$

$\sigma$ - surface tension; $\theta$ - interfacial angle; $g$ - free fall acceleration; $r$ - capillary radius; $\rho$ - density of a liquid.

Frequently accompanied by salt migration crystallization break down into sulphates / chlorides / nitrates (coming from the ground)

Since water moves by capillarity it depends on three aspects

- Capillarity size of the material

- Thickness of the wall

- Evaporation at the wall surface over the area of capillarity rise.

\footnotetext{
${ }^{3}$ the movement of a liquid in the interstices of porous material due to surface tension at the border of solid and liquid; the parameter of capillarity is a height of water movement $\mathbf{h}$
} 
Firstly chemical fumes (Ozone, sulfur dioxide, oxides of nitrogen) in combination with sand, dust, wind (coatings, masonry, metals, polymers). Secondly biostability (bactericidal resistance): the ability of a material to withstand biological influence of inferior plant and low organisms. Thirdly Radiation resistance: the ability of the brick material to withstand different types of sun radiation without changing their properties and destruction.

For this purpose the following assumptions are taken. Plain deformations of a wall in longitudinal or transverse directions are considered; walls represent homogeneous deformable body; undisturbed contact of wall continuous base being deformed is assumed; principle of independence of the influencing factors shall be used: structural deformations of horizontal shear, vertical shear and wall bending induced by ground surface horizontal movement and curvature shall be determined separately in the calculation.

The porosity of the surface varied here, at some places on the wall its higher porosity and the surface roughness the deeper the corrosion process, would take place. Hence, in the process the most active factors are cycling wetting -drying, freezing thawing causing unstable components destruction, micro cracking, and glance loss and finally deterioration can be observed. Hence here corrosion can be decreased.

Carbonated clay $\left(\mathrm{CaCO}_{3}\right)$ destroys under influence of acid rains, alkaline:

$\mathrm{CaCO}_{3}+\mathrm{CO}_{2}+\mathrm{H}_{2} \mathrm{O} \rightarrow \mathrm{Ca}\left(\mathrm{HCO}_{3}\right)_{2}$

$\mathrm{CaCO}_{3}+2 \mathrm{H}_{2} \mathrm{O}+2 \mathrm{SO}_{2} \rightarrow 2\left(\mathrm{CaSO}_{4} 2 \mathrm{H}_{2} \mathrm{O}\right)+2 \mathrm{CO}_{2}$

$\mathrm{CaCO}_{3}+\mathrm{HCl} \rightarrow \mathrm{CaCl}_{2}+\mathrm{H}_{2} \mathrm{CO}_{3}$

$\mathrm{CaCO}_{3}+2 \mathrm{NaOH} \rightarrow \mathrm{NaCO}_{3}+\mathrm{Ca}(\mathrm{OH})_{2}$

Environmental properties: the clay brick used at Mohenjo Daro are disposed to accumulation of raised radionuclide amount in different types of masonry stone and types of stone masonry used at Mohenjo Daro, these are effected by following environmental pollutions.

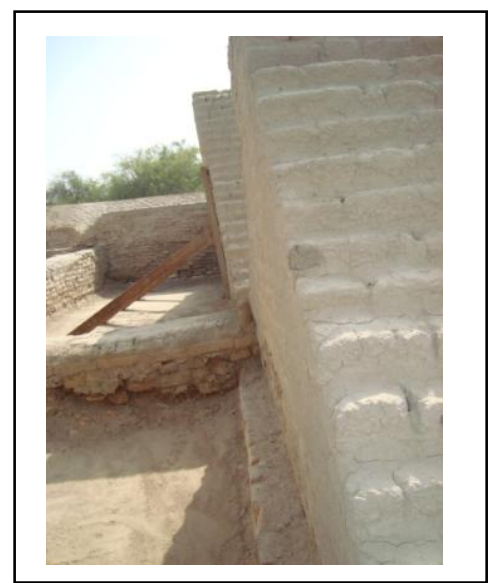

Figure 4: the view of the deformation ( $30^{\text {th }}$ March 2012,

\subsection{Condensation of Moisture}

Condensation of moisture at high relative humanities in brick walls can occur, especially if the dew point is reached within the walls. Condensation of water in capillaries also can occur, especially if the atmosphere relative humidity is $90 \%$ or above. Soluble salts entrapped in brick, however the responsible for the largest amount of hygroscopic (condensed) moisture accumulating in bricks, the amount being several times that condensing in salt free bricks.

\section{WORKING WITH SHEAR WALLS OF MOHENJO- DARO}

The image below shows an example of the Mohenjo Daro typical shear wall analysis in progress. This particular display shows stress intensity and orientation, as well as the deformed configuration (although it is partially obscured in this view). The stress display options can be categorized broadly into how stresses are displayed, and which elements display stress values numerically. The following subsections consider each of these in turn.

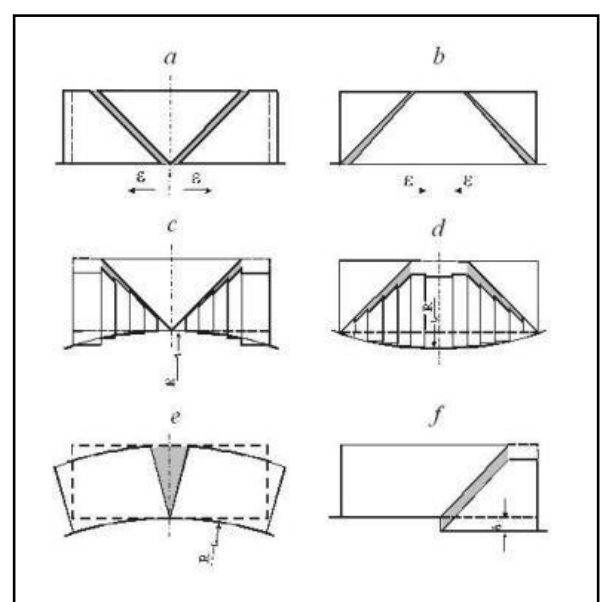

Figure 5. The generalized structural deformations of the walls induced by: a - horizontal shear due to ground surface tension; $\mathrm{b}$ - horizontal shear due to the ground surface compression; $\mathrm{c}-$ vertical shear due to the curvature of convexity; $d$ - vertical shear due to the curvature of concavity; $\mathrm{e}$ - bending due to the curvature of convexity; $\mathrm{f}$ - vertical shear due to the bench formation

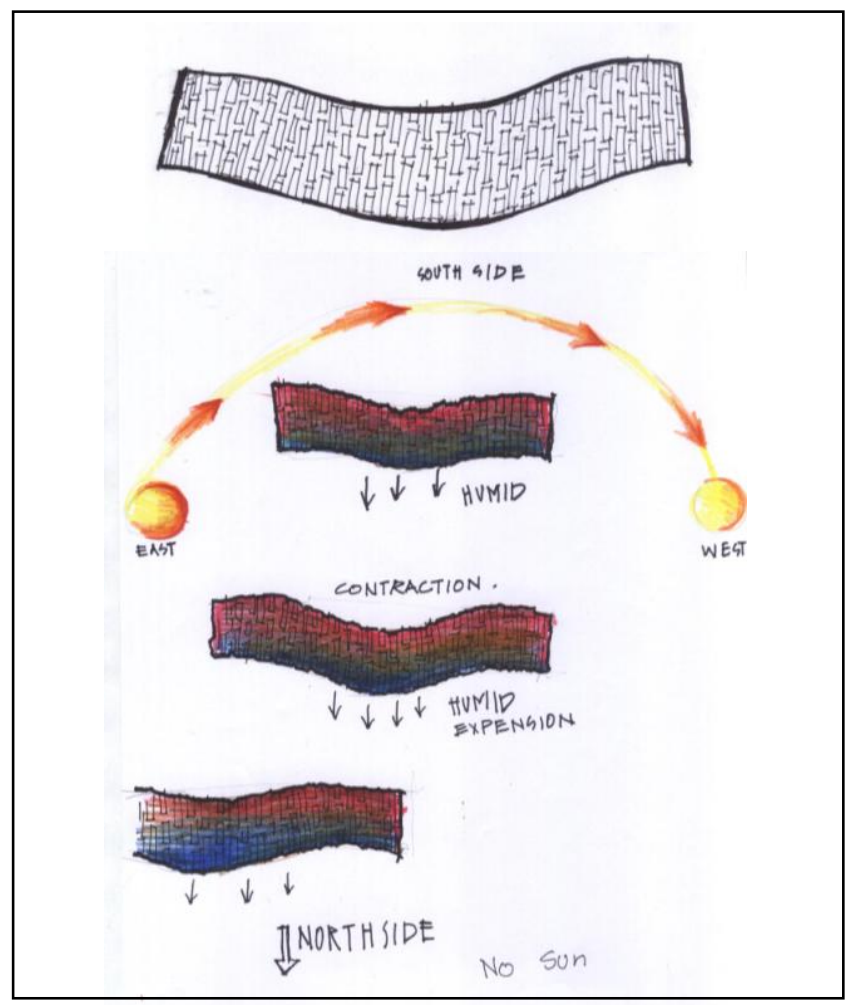

Figure 6: Exaggerated deformation pattern for understanding 


\subsection{Plotting Stresses}

Colour contours can display on the Frame2D software displays both magnitude and direction characteristics of a stress field. The figure below shows a close-up of a stress field. The following representative test cases illustrate the basic performance of the current wall elements: Here the simplest of all cases considered this example will highlight the boundary condition and loading differences between the current elements that are the individual bricks that do not have rotational degrees of freedom due to bonds. In particular, the image below shows the results obtained using a standard uni-axial loading and boundary condition configuration. The next result is the same configuration as above (Fig. 7), but in this case a more refined set of boundary conditions has been applied at the wall so that the corresponding stresses can be considered.

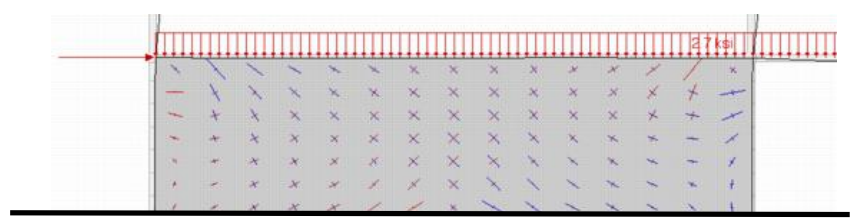

Figure 7: average stress state at different points In the figure above, the small crosses that are drawn at each point represent the average stress state within the corresponding brick group. The crosses are oriented according to the principal directions of the stress state, and each leg of the cross is drawn with a length proportional to the corresponding principal stress. Red indicates tension, and blue indicates compression.

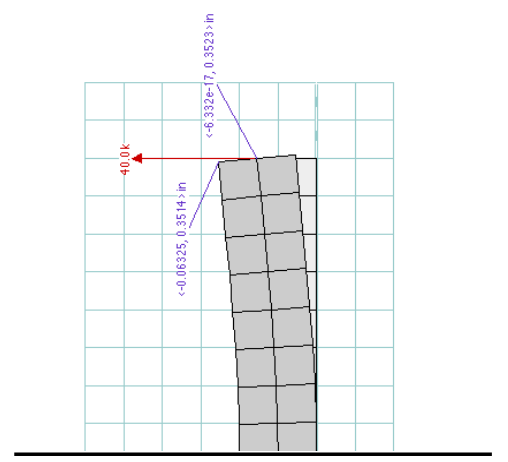

Figure 8. dead constant load of the brick, and bucking effect due to torque

In Fig 8. stresses are shown by plotting lines perpendicular to the maximum in-plane tensile stress direction, with the line lengths proportional to the maximum tensile stress magnitude. Such a depiction can help indicate where cracks might tend to form in materials sensitive to tension. Similarly, choosing the Maximum Shears option leads to the plot below in which the stress are aligned with the directions of maximum shear stress. This depiction can indicate yielding tendencies in ductile brick materials of the wall.

\section{CONCLUSION}

Immediate buttress is needed, which could be easily installed, to stop the inclination several of the supports made up of wood or bamboo could be installed easily by local people using local low cost material and sweet earth to fasten it.

Full repair is required for the 350 walls, for their structures serviceability and engineering support systems and performance properties (replacing structural elements dividing walls, strengthening though sweet earth bricks and bamboo scaffolding).

Running repair is premises appearance, uplift change without replacing its structural elements, (cladding replacement, "facelift" refers to sweet water blasting the surface only).

Damage and wear to the structures can be reduced if the flow of water is controlled. Minor damages can easily be repaired as part of the regular maintenance provided to the remains and its structures. If the flow of water is not properly managed, the deterioration of the structures will be more serious and occur more rapidly. This will lead to higher maintenance demands. An efficient drainage system is therefore essential to allow water to flow off and away from the walls as quickly as possible.

At the time of the inscription of the World Heritage property no precise map of the property was submitted nor were the perimeters of the property provided. To date there is no updated map of the area including the excavated areas.

There is an urgent need to identify the precise boarders of the property along with its buffer zone. Therefore, the mission proposes that the authorities carry out a cross profile in the cardinal directions by dry core drilling $(80 \mathrm{~mm})$ to identify the continuation of the anthropogenic underground deposits.

\section{REFERENCES}

Hughes, R. (1995), "Moenjodaro mission report", unpublished document, UNESCO, Paris. Shaikh, K.H. and Ashfaque, S.M. (1981), Moenjodaro: A 5000-year-old Legacy, UNESCO, Paris.

Harbaugh, (1970).J. and Bonham-Carter, G. Computer simulation in Geology. Wiley-Interscience. New York,

Kerr, H.G. and White, N. (1994), Application of an automatic method for determining normal fault geometries, Journal of Structural Geology, Volume 16, Issue 12, Pages 1691-1709.

Teutonico, J.M. (Ed.) (1985), International Architectural Conservation Course Laboratory Manual, ICCROM, Rome.

Goudie, A.S. (1977), "Sodium sulphate weathering and the disintegration of Moen jodaro, Pakistan", Earth Surface Processes, Vol. 2, pp. 75-85.

Maps are been taken from the further excavation at MohenjoDaro Volume II, Plats 1-CXLVI (E.J.H. Mackay, 1937)

Waltham, D. (1989) Finite-difference modelling of hangingwall deformation. Journal of Structural Geology, Volume 11, Issue 4, Pages 433-437.

\subsection{Acknowledgements}

This project is supported by a Research Laboratory Mohenjo Daro DAK room. To Conservator Mohenjodaro 2013, Ali Hyder for his valuable comments and suggestions. Government of Sindh 